
\title{
25 Research Soure \\ Comparing Infant and Toddler Sleep Patterns Prior To and During The First Wave of Home Confinement Due To COVID-19 in Spain
}

Pia Cassanello ( $\nabla$ mariapiacassanello@gmail.com )

Hospital Universitari General de Catalunya https://orcid.org/0000-0001-7707-2385

Irene Ruiz-Botia

Hospital Universitari General de Catalunya

Pere Sala-Castellvi

Hospital Universitari General de Catalunya

Juan Carlo Martin

Universitat Internacional de Catalunya

Jose Maria Martínez-Sanchez

Universitat Internacional de Catalunya

Albert Balaguer

Universitat Internacional de Catalunya

\section{Research Article}

Keywords: COVID-19 outbreak, early childhood, home confinement, sleep disturbances, sleep patterns

Posted Date: August 23rd, 2021

DOI: https://doi.org/10.21203/rs.3.rs-505674/v2

License: (1) This work is licensed under a Creative Commons Attribution 4.0 International License.

Read Full License

Version of Record: A version of this preprint was published at European Journal of Pediatrics on January 13th, 2022. See the published version at https://doi.org/10.1007/s00431-022-04376-0. 


\section{Abstract}

\section{Introduction:}

Recent literature has shown that sleep patterns are shaped during the first years of life, playing a relevant role in children's functioning. We focused on comparing sleep patterns in infants and toddlers in Spain before and during COVID-19 home confinement to assess the immediate impact on sleep patterns.

\section{Methods}

We compared data from two cross-sectional surveys from parents of 1,658 children three to 36 months of age from Spain. One conducted before COVID-19 $(2017-2018, n=1,380)$ and another during COVID-19 pandemic (March-May of 2020, $n=254$ ). We used an internet self-administrated questionnaire using the Brief Infant Sleep Questionnaire (BISQ) criteria in both surveys.

\section{Results}

During confinement infants and toddlers went to sleep later (median bedtime 21:30 before confinement vs. 21.36 during confinement $(p=0.004)$ ). More infants and toddlers showed longer sleep latencies $(>30$ minutes) during confinement median $33.9 \%$ versus $12.3 \%(p<0.001)$. Based on the recommended BISQ criteria, we observed an increase in poor sleepers meeting at least one criterion of inadequate patterns during confinement $(p<0.001)$. Parental perception of a child's sleep as problematics were $39.4 \%$ and $44.1 \%$ (adjusted $p=0.363$ ) before and under lockdown, respectively.

\section{Conclusions}

Home confinement generally affected infant's and toddler's sleep patterns negatively, however parents didn't report worse perception of sleep quality of their children. Follow-up studies can help understand the potential long-term effects of the COVID-19 pandemic on sleep patterns.

\section{Introduction}

Sleep patterns change rapidly across the earliest years of life and play an important role in children's daytime functioning. There is a growing interest in determining those factors influencing children's sleep development (both intrinsic (i.e., child characteristics) and extrinsic (i.e.environmental input)) $(1,2)$. Cultural norms determine the boundaries between "normal" and "problematic" sleep behavior typically based on the extent to which individuals conform to sleep-schedule and sleep-behavior expectations (3). However, these behavioral patterns might rapidly take a turn-over a in light of external factors such the current public health pandemic due to COVID-19 outbreak. On March 14th 2020, in response to the first wave outbreak, the Spanish Government imposed one of the most stringent lockdowns in Europe (BOE-A- 
2020-3692 https://www.boe.es/eli/es/rd/2020/03/14/463) especially for children, as an emergency measure to prevent further spreading of the infection. After six weeks of strict home confinement, Spanish minors were permitted to leave the house for one hour within allotted time slots and half-mile radius. This sudden unexpected circumstance meant having to adapt to a new reality for both adults and children. Previous literature has found that during non-school period, children tend to be physically less active, have longer screen time, irregular sleep patterns, and less adequate diets, resulting in weight gain and a loss of cardiorespiratory fitness $(4,5)$.

In these recent past months, there is growing evidence being published about the impact of this pandemic on children's health, sleep patterns and psychological development. A meta-analysis on the psychological and behavioral impact of home confinement and quarantine measures during COVID-19 pandemic in 22.996 children/adolescents from diverse European countries, Asian countries and South America showed that $79.4 \%$ of children were affected negatively by the pandemic and quarantine, at least $21.3 \%$ of them had a sleep disturbance (6). A cross-sectional study carried out during the quarantine on 1,143 Spanish and Italian parents of children aged three to 18 years old found that $85.7 \%$ of the parents perceived changes in their children's emotional state and behaviors. The most frequent symptoms were difficulty concentrating $(76.6 \%)$, boredom $(52 \%)$, irritability (39\%), restlessness (38.8\%), nervousness (38\%), feelings of loneliness (31.3\%), uneasiness (30.4\%), and worries (30.1\%). Spanish parents reported more symptoms than Italians ones (7).

When analyzing preschoolers sleep patterns during home confinement, a recent cross-sectional study on 412 infants and toddlers $0-35$ months from several mainly European countries described an acute decrease in sleep quality. At follow-up (one and two months later), this effect rebounded to the level reported for the period before the home confinement. Caregiver's stress level was also identified as a substantial risk factor determining lower sleep quality (8). However, most of the literature currently available has highlighted the short-term effects of COVID-19 restrictions, but not reporting information on sleep quality before home confinement on the same sample.

The aim of this work is to compare two similar samples of infant and toddlers in Spain three to 36 months of age (before and during COVID-19 confinement) in order to identify possible sleep pattern changes related to the COVID-19 confinement context. We hypothesize to find a negative impact on infants and toddlers sleep patterns during the COVID-19 confinement.

\section{Methods}

We analyzed a repeated cross-sectional survey of parents who reported having a healthy infant/toddler between three and 36 months of age in Spain. One conducted before COVID-19 confinement (2017-2018) (9) and another conducted during the strict home confinement of the first wave of COVID-19 (March-May of 2020). We used an internet self-administrated questionnaire assessing sleep patterns using the Spanish validated Brief Infant Sleep Questionnaire (BISQ) criteria $(10,11)$ in both surveys. The sample 
recruitment, the inclusion and exclusion criteria as well as the variables measured and analyses mirrored our previous study in order to be able to perform adequate comparisons between both our samples (9).

\section{Participants}

We compared 1,634 infants and toddlers recruited in two different stages $(1,380$ before confinement (February 2017-February 2018) and 254 during confinement (April-June 2021). Both samples included healthy Spanish children between ages three to 36 months. Data were collected from a digital online questionnaire available within a free-access website. Parents were invited to participate either during their child's paediatric follow-up visit at Hospital Universitari General de Catalunya or through online freeaccess parental support groups.

\section{Measures:}

Parents completed a self-reported 47 item online questionnaire, which included the Spanish validated Brief Infant Sleep Questionnaire (BISQ-E) (11) (based on the BISQ (10).

In order to understand developmental patterns and resembling the original BISQ methodology (10), children were grouped in five age ranges as initially done in the BISQ validation. Group one was ages three to six months; group two, ages seven to 12 months; group three, ages 13 to 18 months; group four, ages 19 to 24 months; group five, ages 25 to 36 months.

Based on the BISQ criteria established for clinically classifying poor sleepers (10) (more than three awakenings a night, nocturnal awakenings longer than one hour and, a total sleep time of less than nine hours), where any of these indications in a child suggests the need for further follow-up, we used this same criterion for defending problematic sleep behaviour. Parental perception of sleep quality was also included in the analysis as a variable present in the original BISQ (10).

\section{Procedure}

The Institutional Ethics Review Board at Hospital Universitari General de Catalunya and Universitat Internacional de Catalunya, Barcelona approved this study. All users provided consent to the inclusion of their data in the present research study and were able to decline participation at all times. The researchers provided users with contact information should they have any questions, concerns or desire to withdraw consent. Data form second cross-sectional sample were collected from April 2020 to June 2020.

For this study, a self-registered website domain was created called www.epison.es where the questionnaire was uploaded and encrypted. The completion of the questionnaire was voluntary and parents were not offered any compensation for their participation. Inclusion criteria were parents with infants and toddlers from three to 36 months of age residing in Spain. Exclusion criteria were limited to literacy in Spanish language.

\section{Analyses}


The variables were described with frequency and percentage for the qualitative variables, the mean and standard deviation for the quantitative normal-distributed variables, and median and interquartile range for the quantitative not normally distributed variables.

To compare two groups (before and during confinement, for example) a prevalence ratio was calculated for qualitative variables, with their confidence interval and p-value; a Mann-Whitney test was performed for quantitative not normally distributed variables.

The confidence intervals were calculated with a level of confidence of $95 \%$. The tests were considered significant when the p-value is under 0.05 . The normality was tested with the Shapiro-Wilk test and the Kolmogorov-Smirnov test. All the analyses were performed with R Statistical Software version 3.5.1 for MAC.

\section{Results}

Both samples of infants and toddlers were distributed regarding age in months as following: infants and toddlers age three-six months $13.8 \%$, seven- 12 months $20.4 \%$, $13-18$ months $17.3 \%, 19-24$ months $14.6 \%$ and $25-36$ months $33.9 \%$. Further data on demographics are presented in Table 1. 
Table 1

Demographics among both samples (before and during confinement sample)

\begin{tabular}{|c|c|c|c|}
\hline & $\begin{array}{l}\text { Before confinement } \\
n=1,380\end{array}$ & $\begin{array}{l}\text { During confinement } \\
n=254\end{array}$ & P-value \\
\hline & $\%$ & $\%$ & \\
\hline Child's sex & & & $0.960 *$ \\
\hline Male & 52.0 & 52.4 & \\
\hline Female & 48.0 & 47.6 & \\
\hline \multirow[t]{2}{*}{ Child's age months (mean) } & $19.2(9.3)$ & $18.8(9.9)$ & $0.551^{* *}$ \\
\hline & & & $0.100^{\star}$ \\
\hline $3-6$ & 11.1 & 13.8 & \\
\hline $7-12$ & 17.3 & 20.4 & \\
\hline $13-18$ & 17.9 & 17.3 & \\
\hline $19-24$ & 21.4 & 14.6 & \\
\hline $25-36$ & 32.2 & 33.9 & \\
\hline Respondent's education: & & & $<0.001^{*}$ \\
\hline University degree & 64.0 & 77.5 & \\
\hline High school degree & 25.4 & 15.0 & \\
\hline Primary education & 10.6 & 7.5 & \\
\hline \multirow[t]{2}{*}{ Respondent's age months (mean) } & $34.6(4.6)$ & $35.4(4.4)$ & $0.008^{\star *}$ \\
\hline & & & $<0.001^{*}$ \\
\hline$<25$ & 1.5 & 10.2 & \\
\hline $25-35$ & 57.0 & 44.5 & \\
\hline$>35$ & 41.5 & 45.3 & \\
\hline \multicolumn{4}{|l|}{ * Chi square test } \\
\hline 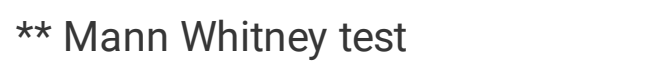 & & & \\
\hline
\end{tabular}

Table 2 compares sleep patterns and ecology before and during confinement. We found that during confinement, infants and toddlers went to sleep later than similar population under no confinement: median bedtime 21:30 (IQR 21-22) before confinement vs. 21:36 bedtime (IQR 21-22:30) during confinement $(p=0.004)$. This finding was also significant when considering the youngest infant group 
(3-6 months of age) with median bedtime 21:24 (IQR 20:48.8-22:18) before confinement vs. median bedtime 22:00 (IQR 21:30 - 23) during confinement $(p=0.017)$ ) and the oldest toddler group (25-36 months of age) (median bedtime 21:36 (IQR 21:18-22:06) before confinement vs. median bedtime 22:00 (IQR 21:30 - 22:36) during confinement $(p<0.001)$ ). (see Supplementary tables: Table A. Bedtime).

Regarding total sleep time, we found a tendency for less total sleep time during confinement (12.0 hours (IQR 11.0-13.0) before confinement vs. 12.0 hours (IQR 11.0-12.7) during confinement) however non statistically significant $(p=0.078)$. 
Table 2

Comparison on sleep patterns and ecology among both samples (before and during confinement)

\begin{tabular}{|c|c|c|c|c|c|c|c|}
\hline & \multicolumn{2}{|c|}{$\begin{array}{l}\text { Before confinement ( } \mathrm{n} \\
=1380 \text { ) }\end{array}$} & \multicolumn{2}{|c|}{$\begin{array}{l}\text { During confinement } \\
(n=254)\end{array}$} & \multicolumn{2}{|c|}{ comparison } & \multirow[b]{2}{*}{$\begin{array}{l}p- \\
\text { value**}\end{array}$} \\
\hline & Median & IQR & Median & IQR & & & \\
\hline \multirow[t]{2}{*}{ Bedtime } & $21: 30$ & $(21.0 ; 22.0)$ & $21: 36$ & $\begin{array}{l}(21.0 \\
22.5)\end{array}$ & & & 0.004 \\
\hline & $\%$ & Cl 95\% & $\%$ & $\mathrm{Cl} 95 \%$ & $\mathrm{PR}^{\star}$ & $\begin{array}{l}95 \% \mathrm{Cl} \\
\mathrm{PR}\end{array}$ & $p$-value \\
\hline $\begin{array}{l}\text { Total sleep time }<9 \\
h^{\star \star \star \star}\end{array}$ & 2.3 & $(1.59 ; 3.26)$ & 2.8 & $\begin{array}{l}(1.11 ; \\
5.59)\end{array}$ & 1.03 & $\begin{array}{l}(0.39 \\
2.34)\end{array}$ & 0.950 \\
\hline $\begin{array}{l}>3 \text { night } \\
\text { awakenings }\end{array}$ & 15.7 & $\begin{array}{l}(13.84 \\
17.75)\end{array}$ & 12.6 & $\begin{array}{l}(8.78 ; \\
17.32)\end{array}$ & 0.77 & $\begin{array}{l}(0.51 ; \\
1.09)\end{array}$ & 0.153 \\
\hline $\begin{array}{l}\text { Duration of } \\
\text { awakenings }>1 \mathrm{~h}\end{array}$ & 16.7 & $\begin{array}{l}(14.80 \\
18.81)\end{array}$ & 9.8 & $\begin{array}{l}(6.47 ; \\
14.18)\end{array}$ & 0.57 & $\begin{array}{l}(0.36 ; \\
0.86)\end{array}$ & 0.011 \\
\hline $\begin{array}{l}\text { sleep onset latency } \\
>30 \mathrm{~min}\end{array}$ & 12.3 & $\begin{array}{l}(10.63 \\
14.17)\end{array}$ & 33.9 & $\begin{array}{l}(28.06 \\
40.04)\end{array}$ & 2.81 & $\begin{array}{l}(2.13 \\
3.67)\end{array}$ & $<0.001$ \\
\hline \multicolumn{8}{|c|}{ “Inadequate" sleep patterns ${ }^{\star \star \star: ~}$} \\
\hline 0 items & 65.3 & $\begin{array}{l}(62.71 ; \\
67.80)\end{array}$ & 52.4 & $\begin{array}{l}(46.02 ; \\
58.64)\end{array}$ & 0.81 & $\begin{array}{l}(0.67 ; \\
0.98)\end{array}$ & 0.029 \\
\hline 1 items & 25.0 & $\begin{array}{l}(22.73 \\
27.37)\end{array}$ & 37.8 & $\begin{array}{l}(31.81 ; \\
44.07)\end{array}$ & 1.49 & $\begin{array}{l}(1.17 ; \\
1.88)\end{array}$ & $<0.001$ \\
\hline$\geq 2$ items & 9.7 & $\begin{array}{l}(8.20 ; \\
11.39)\end{array}$ & 9.8 & $\begin{array}{l}(6.47 ; \\
14.18)\end{array}$ & 0.95 & $\begin{array}{l}(0.59 \\
1.47)\end{array}$ & 0.844 \\
\hline \multicolumn{8}{|c|}{ Parental perception of a child's sleep problem: } \\
\hline A small problem & 21.4 & $\begin{array}{l}(19.24 \\
23.63)\end{array}$ & 24.0 & $\begin{array}{l}(18.89 \\
29.75)\end{array}$ & 1.10 & $\begin{array}{l}(0.82 \\
1.45)\end{array}$ & 0.525 \\
\hline $\begin{array}{l}\text { A very serious } \\
\text { problem }\end{array}$ & 18.1 & $\begin{array}{l}(16.12 ; \\
20.25)\end{array}$ & 20.0 & $\begin{array}{l}(15.33 \\
25.54)\end{array}$ & 1.11 & $\begin{array}{l}(0.81 ; \\
1.51)\end{array}$ & 0.502 \\
\hline $\begin{array}{l}\text { A small + a very } \\
\text { serious }\end{array}$ & 39.4 & $\begin{array}{l}(36.90 \\
42.13)\end{array}$ & 44.1 & $\begin{array}{l}(37.89 \\
50.34)\end{array}$ & 1.10 & $\begin{array}{l}(0.89 \\
1.35)\end{array}$ & 0.363 \\
\hline \multicolumn{8}{|l|}{ *PR: Prevalence Ratio } \\
\hline \multicolumn{8}{|l|}{ ** Mann-Whitney test } \\
\hline \multicolumn{8}{|c|}{ 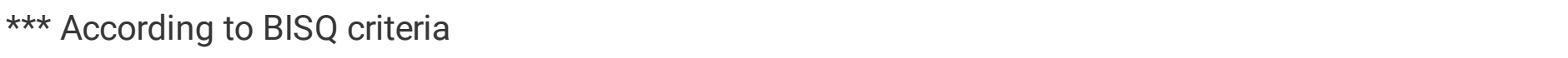 } \\
\hline$\star \star \star \star$ One missing da & r total sl & p time & & & & & \\
\hline
\end{tabular}


In Table 2, prevalence of infants and toddlers presenting with the criteria used in the original BISQ to define poor sleepers are presented (10) (total sleep time $<9$ hours, $>3$ nights awakenings, duration of awakenings $>1$ hour) as well as sleep onset latency longer than 30 minutes both before and during COVID-19 confinement. Results were adjusted for age distribution of our sample, sex and parental level of education. We found more infants and toddlers presenting with a sleep latency longer than 30 minutes during confinement $(p<0.001)$. However, we found a decrease in infants and toddlers presenting with longer than one hour nocturnal awakenings: $16.7 \%$ (IQR 14.8-18.8) before confinement vs. 9.8\% (IQR 6.47-14.18) during confinement $(p=0.011)$.

Based on the mentioned BISQ criteria for classifying inadequate sleep patterns, we categorised both samples of infants and toddlers in three groups (i) none, ii) one of the poor sleeper BISQ criteria and iii) two or more poor sleeper BISQ criteria. We observed a statistically significant increase in infants and toddlers showing criteria for classifying poor sleepers during confinement $(p<0.001)$. Therefore, during COVID-19 home confinement infants and toddlers showed longer sleep latency, later bedtime and more criteria for classifying poor sleepers as defined in the original BISQ (more than three awakenings a night, nocturnal awakenings longer than one hour and, a total sleep time of less than nine hours (10).

In Table 2 we also compare parental perception of the child's sleep problem before confinement and during confinement. A trend of increasing parental perception of a child's sleep as problematic was observed (39.4\% of parents referring their child had a sleep problem before confinement vs. $44.1 \%$ of parents during confinement) however not statistically significant (adjusted $p=0.363$ ).

In the supplementary tables, the main variables regarding sleep patterns (sleep time, bedtime, number and duration of nocturnal wakefulness, short sleep time, sleep latency and parental perception) were presented adjusted for sex and age of child, level of education, age of the respondent, as well as parental perception of sleep difficulty.

Regarding sleep onset latency $>30$ minutes, we found statistically significant differences in both samples globally $(12.3 \%$ of infants and toddlers presenting a sleep onset latency $>30$ minutes before confinement vs. $33.8 \%$ during confinement $(p<0.001)$. This difference were also found when comparing both sexes, all age groups and among parents with a university degree ( $10.6 \%$ before confinement vs. $38.7 \%$ during confinement $(p<0.001)$. (See supplementary tables: Table E: Sleep onset latency $>30$ minutes).

We found no statistically significant differences in daytime napping (p-value $=0.090)$. In both samples before confinement and during confinement, daytime napping lasted a median of 2 hours, the same first quartile $(1 \mathrm{~h} 30 \mathrm{~m})$ and just 15 minutes of difference in the third quartile (3 hours before home confinement and 2 hours 45 minutes during confinement).

\section{Discussion}

To the best of our knowledge, this is the first age specific comparative study on infant and toddler sleep patterns before the COVID-19 pandemic and during confinement due to COVID-19 pandemic. 
Adequate sleep patterns in infants and toddlers are relevant as they are linked to proper and long-term social-emotional development. A previous study found that later bedtimes and less total sleep across the 24-hour period predicted higher internalizing problem scores (including indices of depression/withdrawal, general anxiety, separation distress, and inhibition) (12). Regarding sleep patterns in pediatrics specifically during the COVID-19 pandemic, recent literature has found that changes in sleep patterns are diverse and no unified change for the worse can actually be expected.

Total sleep time is a relevant variable in describing children sleep patterns. In our study, we found a decreasing trend in total sleep time for all age groups during confinement however statistically significant differences were only found in the youngest infant group (three-six months) with a median duration of total sleep time before confinement of 13 hours (IQR 11.5-14.5) vs. median of 12 hours during confinement (IQR 11.1-13.2) as well as in the oldest toddler group (25-36 months) with a median duration of total sleep time before confinement of 11.5 hours (IQR 10.7-12.0) vs. 11.0 hours (IQR 1012). Similarly, in a recent study analysing sleep patterns in Spanish children of relatively comparable age (0-2 years of age) during home confinement, total sleep time reported was mean of 10.98 hours; (SD = 1.8) (13), Another research based in Spain on sleep patterns during COVID-19 pandemic analyzing 280 children from 0-4 years of age, described a mean sleep time in infants younger than one year of 11.69 hours $(S D=1.87)$ and among $1-2$ years 11.35 hours $(S D=1.74)(14)$. Lecuelle (15) found in French preeschoolers that during home confinement, the length of nocturnal sleep increased from 10.3 to 10.9 hours however with no impact on the total duration of sleep over 24 hours.

Regarding adequacy of sleep duration in our sample, and based on the WHO guidelines for children younger than five years as reference (16) (infants younger than one year of age should sleep a minimum of 12 hours of total sleep time and from 1 to 2 years of age a minimum of 11 hours), remarkably in our research a quarter of them did not reach this total sleep time of 12 hours (IQR 11-12.7).

Difficulties initiating and maintaining sleep increased in our study, finding that infants and toddlers during confinement went to bed slightly later. This fact was especially substantial in both the youngest infants and the oldest toddlers. We also found longer sleep onset latencies (>30 minutes) during COVID19 confinement, with infants and toddlers showing more difficulty to fall asleep. Interestingly, however, prolonged nocturnal awakening of more than 1 hour decreased. Previous literature has already described similar findings regarding infants and toddlers with delayed bedtime being significantly associated with bedtime resistance even when adjusting for total sleep time $(13,17)$.

A study examining 3157 preschoolers in Chile found that during early stages of the pandemic, sleep duration increased, and sleep quality declined. Toddlers and preschoolers with space to play at home and living in rural areas experienced an attenuated impact of the pandemic restrictions on their physical activity levels, screen time, and sleep quality (18). Therefore, home confinement might play a role in regulating sleep patterns intertwined with other variables previously described such as sleep light, activity level, social contact, psychological well-being among others $(7,14,19)$. Previous literature has also pointed out that low optimism and parental stress correlates negatively with sleep duration and parental 
perception of sleep quality (20) as well as the potential influence of longer screen time exposure in explaining later bedtimes $(14,19)$.

The original BISQ Questionnaire (10) described very concrete sleep patterns that might indicate the need for a child to be further screened for sleep difficulties (total sleep time less than nine hours, more than three night awakenings and duration of awakenings longer than one hour). When comparing infants and toddlers presenting with one or more of these criteria in both samples we found a statistically significantly increase of infants and toddlers presenting with one of this sleep criteria during COVID confinement ( $37 \%$ of infants and toddlers vs. $25 \%$ before COVID-19 confinement) $(p<0.001)$.

Regarding parental perception of sleep difficulties, $44 \%$ of parents evaluated during COVID-19 confinement indicated their child had a sleep problem whereas $39 \%$ of parents stated sleep difficulties before COVID-19 confinement. Zreik (21) analyzed in Israel the possible negative implications for sleep during COVID-19 pandemic both for mothers and infants and toddlers 6-72 months of age, finding that about $30 \%$ of mothers reported a negative change in child's sleep quality and a decrease in sleep duration. However there were also mothers who reported a positive change in sleep quality during COVID19 pandemic (21).

There were some limitations to the present study. Home confinement in Spain took place between MarchMay 2021, however we recruited our sample from April-June 2021 after receiving approval from our Ethics Committee, therefore a memory bias in this short time span might be taken into account. Both samples (before confinement and during confinement) showed slight differences in some characteristics such as a slightly uneven proportion of toddlers among 19-24 months of age in both samples $(21 \%$ before confinement vs. $14 \%$ during confinement $(p=0.026))$, a higher proportion of parents with a university degree $(64 \%$ before confinement vs. $77 \%$ during confinement $(p<0.001))$ and a higher percentage of parents younger than 25 years of age (1.5\% before confinement vs. $10 \%$ during confinement $(p<0.001))$. This might be probably due to the relatively smaller sample recruited during confinement. However, methodologically in both groups we followed same procedural guidance.

Our sample may have a limited generalizability as participants were recruited by convenience sampling and were mostly living in the region of Catalonia in Spain. Regarding demographical characteristics, sample size limitations have to be noted. Despite this limitation, the results in this current research showed statistical significance. Our sample included an unbalanced proportion of families with higher education, as can be expected from a primarily internet-based study. Nevertheless, our findings were consistent with previous cross-cultural web-based studies $(10,22,23)$, showing similar epidemiological characteristics so we believe we have obtained similar segments of the population within our country for purposes of cross-cultural comparison $(10,23)$. For the present research we based the definition of sleep difficulties solely on the criteria presented in the BISQ (10) thus not taking into account other aspects of this complex construct. We used a limited number of sleep variables to define sleep ecology without taking into account further variables that have shown to have a predictor value for sleep quality such as the use of routines, parental stress during COVID-19 pandemic as well as sociodemographic relevant data 
such as size of living unit, income, housing location and space, remote-working of one or both parents among others.

The reliance on parental reports in assessing infant sleep has inherent limitations; however previous research $(24,25)$ has shown a high correlation between parent-reported sleep duration and actigraphyrecorded sleep duration in young healthy children. Further, parents with concern about their child's sleep may have been more likely to participate, skewing this aspect of our results. Information bias may be an inherent limitation to web-based surveys. However, the fact that there was not an interviewer carrying out the questionnaire may have decreased an unacceptability bias (26).

\section{Conclusions}

These results suggest that confinement due to COVID-19 pandemic had a significant impact on infants' and toddler's sleep during the initial wave in Spain. In light of these findings, sleep habits need constant consideration along a child's development as a changing environment and context such as the COVID-10 pandemic has shown to have a considerate impact among a short time span. Follow-up studies focusing on infant's and toddler's sleep patterns might help assess the potential long-term effects of the COVID-19 pandemic.

\section{Declarations}

Funding: The present research received no funding.

All authors state having no conflicts of interest / no competing interests to carry out the present research

Availability of data and material: The databased created for the study is available upon request

Code availability: N/A

Authors' contributions: Cassanello Pia and Balaguer Albert had primary responsibility for protocol development, sample enrolltment, outcoment assessment, premilinary data analysis and writing the manuscript. Drs. Ruiz-Botia Irene and Sala-Castellvi Pere participated in the enrollment as well as analytical framework for the study and contributed to the writing of the manuscript.Martin Juan Carlos and Martínez-Sanchez Jose María supervised the design and execution of the study, performed the data analyses and contributed to the writing of the manuscript

Ethics approval: The Institutional Ethics Review Board at Hospital Universitari General de Catalunya and Universitat Internacional de Catalunya, Barcelona approved this study.

Consent to participate: All users provided consent to the inclusion of their data in the present research study and were able to decline participation at all times. The researchers provided users with contact information should they have any questions, concerns or desire to withdraw consent. 


\section{Consent for publication; N/A}

\section{Author Statement:}

Cassanello Pia and Balaguer Albert had primary responsibility for protocol development, sample enrolltment, outcoment assessment, premilinary data analysis and writing the manuscript

Drs. Ruiz-Botia Irene and Sala-Castellvi Pere participated in the enrollment as well as analytical framework for the study and contributed to the writing of the manuscript.

Martin Juan Carlos ${ }^{2}$ and Martínez-Sanchez Jose María supervised the design and execution of the study, performed the data analyses and contributed to the writing of the manuscript.

\section{References}

1. Camerota M, Propper C, Teti, Douglas. Intrinsic and extrinsic factors predicting infant sleep: Moving beyond main effects. Developmental Review. 2019; 53

2. Sette S, Baumgartner E, Ferri R, Bruni O (2017) Predictors of sleep disturbances in the first year of life: a longitudinal study. Sleep Med 36:78-85

3. Oskar J, O'Connor B (2005) Children's sleep: an interplay between culture and biology. Pediatrics 115:204-216

4. Brazendale K, Beets MW, Weaver RG et al (2017) Understanding differences between summer vs. school obesogenic behaviors of children: the structured days hypothesis. Int J Behav Nutr Phys Act $14: 100$

5. Cartanyà-Hueso À, Lidón-Moyano C, Cassanello P, Díez-Izquierdo A, Martín-Sánchez JC, Balaguer A, Martínez-Sánchez JM (2021) Smartphone and Tablet Usage during COVID-19 Pandemic Confinement in Children under 48 Months in Barcelona (Spain). Healthcare (Basel) 9(1):96

6. Panda PK, Gupta J, Chowdhury SR, Kumar R, Meena AK, Madaan P, Sharawat IK, Gulati S. Psychological and Behavioral Impact of Lockdown and Quarantine Measures for COVID-19 Pandemic on Children, Adolescents and Caregivers: A Systematic Review and Meta-Analysis. J Trop Pediatr. 2021;67(1)

7. Orgilés M, Morales A, Delvecchio E, Mazzeschi C, Espada JP (2020) Immediate Psychological Effects of the COVID-19 Quarantine in Youth From Italy and Spain. Front Psycho 11:579038

8. Markovic A, Mühlematter C, Beaugrand M, Camos V, Kurth S. Severe effects of the COVID-19 confinement on young children's sleep: A longitudinal study identifying risk and protective factors. $J$ Sleep Res. 2021;18

9. Cassanello P, Ruiz-Botia I, Díez-Izquierdo A et al (2020) How do infants and toddlers sleep in Spain? A cross-sectional study. Eur J Pediatr 180(3):775-782

10. Sadeh A. A brief screening questionnaire for infant sleep problems: validation and findings for an internet sample. Pediatrics 2004; 113 
11. Cassanello P, Díez-Izquierdo A, Gorina N, Matilla-Santander N, Martínez-Sanchez JM, Balaguer A (2018) Adaptación y estudio de propiedades métricas de un cuestionario de valoración del sueño para lactantes y preescolares. An Pediatría 89(4):230-237

12. Mindell JA, Leichman ES, DuMond C, Sadeh A (2017) Sleep and Social-Emotional Development in Infants and Toddlers. J Clin Child Adolesc Psychol 46(2):236-246

13. Cachón-Zagalaz J, Zagalaz-Sánchez Mª L, Arufe-Giráldez V, Sanmiguel-Rodríguez A, González-Valero G (2021) Physical Activity and Daily Routine among Children Aged 0-12 during the COVID-19 Pandemic in Spain. Int J Environ Res Public Health 18:703

14. Arufe-Giráldez V, Sanmiguel-Rodríguez A, Zagalaz-Sánchez ML, Cachón-Zagalaz J, Gonzalez-Valero G Sleep, physical activity and screens in 0-4 years Spanish children during the COVID-19 pandemic. Were the WHO recommendations met? Journal Human Sport and Exercise. 2020; 0

15. Lecuelle F, Leslie W, Huguelet S, Franco P, Putois B (2020) Did the COVID-19 lockdown really have no impact on young children's sleep? J Clin Sleep Med 16(12):2121

16. World Health Organization. (2019). Guidelines on physical activity, sedentary behaviour and sleep for children under 5 years of age. World Health Organization. https://apps.who.int/iris/handle/10665/311664. Licencia: CC BY-NC-SA 3.0 IGO

17. Kitamura, 2015) Enomoto S, Kamei M Y, et al. Association between delayed bedtime and sleeprelated problems among community-dwelling 2-year-old children in Japan. J Physiol Anthropol. 2015;34(1):12

18. Aguilar-Farias N, Toledo-Vargas M, Miranda-Marquez S, Cortinez-O'Ryan A, Cristi-Montero C, Rodriguez-Rodriguez F, Martino-Fuentealba P, Okely AD (2020 Dec) Del Pozo Cruz B. Sociodemographic Predictors of Changes in Physical Activity, Screen Time, and Sleep among Toddlers and Preschoolers in Chile during the COVID-19 Pandemic. Int J Environ Res Public Health 29(1):176 18(

19. Moore SA, Faulkner G, Rhodes RE, Brussoni M, Chulak-Bozzer T, Ferguson LJ, Mitra R, O'Reilly N, Spence JC, Vanderloo LM, Tremblay MS (2020) Impact of the COVID-19 virus outbreak on movement and play behaviours of Canadian children and youth: a national survey. Int $\mathrm{J}$ Behav Nutr Phys Act 17(1):85

20. Miadich SA, Doane LD, Davis MC, Lemery-Chalfant K (2019) Early parental positive personality and stress: Longitudinal associations with children's sleep. Br J Health Psychol 24(3):629-650

21. Zreik G, Asraf K, Haimov I, Tikotzky L (2021 Feb) Maternal perceptions of sleep problems among children and mothers during the coronavirus disease 2019 (COVID-19) pandemic in Israel. J Sleep Res 30(1):e13201

22. Sadeh A, Mindell JA, Luedke K, Wiegand B (2009) Sleep and sleep ecology in the first 3 years: a webbased study. J Sleep Res 18(1):60-73

23. Mindell JA, Sadeh A, Wiegand B, How TH, Goh DYT (2010) Cross-cultural differences in infant and toddler sleep. Sleep Med 11(3):274-280 
24. Lomeli HA, Pérez-Olmos I, Talero-Gutiérrez C, Moreno CB, González-Reyes R, Palacios L, de la Peña F, Muñoz-Delgado J (2008) Sleep evaluation scales and questionaries: a review. Actas Esp Psiquiatr 2008; 36(1):50-59

25. Lewandowski AS, Toliver-Sokol M, Palermo TM (2011) Evidence-based review of subjective pediatric sleep measures. J Pediatr Psychol 2011;36(7):780-793

26. Díaz de Rada V (2018) Problemas de representatividad en las encuestas con muestreos probabilísticos. Pap Rev School 74:45

\section{Supplementary Files}

This is a list of supplementary files associated with this preprint. Click to download.

- Supplementarytables.docx 